\title{
ANÁLISIS ARTEFACTUAL DE LOS PANELES CON QUILCAS DE MANT'O, CUSCO, PERÚ
}

\author{
CARLOS RODRÍGUEZ BÉJAR \\ Universidad NaCIONAL SAN ANTONIO ABAD DEL CUSCO \\ carlos2kalinn@gmail.com
}

\section{RESUMEN}

El presente artículo tiene la finalidad de mostrar los resultados comparativos entres paneles de arte rupestre del sitio arqueológico de Mant'o. Para este fin se recurrió al método artefactual que permite identificar a la quilca como un artefacto con categorías independientes susceptibles a medición, lo que permitió la comparación entre imágenes de diferentes paneles.

Palabras Claves: Artefactual, arte rupestre, quilca, ortofoto.

\section{Abstract}

This article has the purpose of showing the comparative results among panels of rock art of the archaeological site of Mant'o. For this purpose we used the artifactual method that allows the identification of the quilca as an artifact with independent categories susceptible to measurement, which allowed the comparison between images of different panels.

KEYwords: Artefactual, rock art, quilca, orthophoto.

\section{INTRODUCCIÓN}

El estudio del arte rupestre, o como los investigadores lo conocemos en el Perú: Quilcas, suelen ser muy especulativo, probablemente por la falta de métodos científicos que nos permitan identificar la cronología del material a estudiar. Sin embargo, desde la fundación del APAR (Asociación Peruana de Arte Rupestre), se empezó a cambiar los paradigmas de esta investigación, siendo el tema cronológico uno de los que cobró más importancia.

Uno de los métodos que nos ayuda a definir en el aspecto temporal de las Quilcas, es el análisis artefactual que fue diseñado por el arqueólogo Gori Tumi Echevarría López (2003, 2008), que permite realizar un análisis amplio de esta evidencia, descomponiendo un todo en partes disgregadas para po- 
der estudiar su estructura formal. De esta manera se puede examinar individualmente cada una de las imágenes en la roca, realizando una comparación de forma y diseño, lo que permite analizar de forma cualitativa y comparativa los paneles con quilcas; hasta llegar a conocer los elementos y principios de realización de esta evidencia.

Este tipo de análisis se realizó en los paneles con quilcas de Mant'o (Cusco - Lares), como parte del trabajo de tesis de licenciatura del autor (Rodríguez 2016), siendo la finalidad de este artículo, demostrar que es posible identificar diferentes patrones gráficos en un mismo sitio arqueológico con quilcas o arte rupestre con la ayuda de método artefactual.

\section{UBICACIÓN}

El sitio de Mant'o se encuentra políticamente ubicada en la región del Cusco, provincia de Calca, distrito de Lares y comunidad campesina de Mantinga. Geográficamente se ubica en la confluencia de los ríos Lares y Amparaes, que dan lugar al río Yanatile. El panel principal con quilcas (Panel N01), junto a otros dos paneles aledaños, se encuentra en el cerro denominado Mant'o. Otro panel asociado (Panel № 05) se encuentra en las laderas de la montaña Loaq'ay en la margen izquierda del río Lares. El sitio fue estudiado anteriormente por Rodrigo y Huarcaya (2003).

\section{Metodología}

Para realizar las comparaciones entre diferentes paneles aplicamos el método llamado "perspectiva artefactual". Lo que va permitir identificar los pictogramas como artefactos, con categorías analíticas interdependientes que identifican atributos observables del artefacto, en este caso la técnica, la forma y el estilo.

Según Echevarría-López, estos atributos, una vez definidos:

"pueden ser utilizados en estudios comparativos sin perjuicio de su naturaleza artística, lo cual es de utilidad crucial en la investigación arqueológica. Un estudio del tipo, entonces, nos permitirá establecer en forma llana las características naturales (físicas) de los motivos que pueden ser usados como variables en un estudio científico.

Esta aproximación se dice "artefactual", porque en efecto, utiliza las tres características básicas (intrínsecas) que todo artefacto posee; las cuales son: técnica, forma y estilo. Aunque el número de categorías puede ser ampliado de acuerdo a la extensión de los estudios, en forma de nuevas variables analíticas (...); consideramos que estas tres categorías, sumadas a las que incorporaremos después, son el suficientemente consistentes como para poder resolver los problemas planteados y alcanzar los objetivos de la investigación..." (Echevarría-López 2008: 21).

Para el registro de las quilcas se hicieron observaciones visuales directas, cuadernos y fichas de campo, así como fotografía convencional y ortofotos. Se tomó en cuenta el entorno tratando de no hacer alteraciones durante nuestra visita de estudios.

\section{Panel № 01 Mant'o}

Este panel presenta dos hileras de 15 motivos zoomorfos, que probablemente representan camélidos sudamericanos (Fig. 1). Están graficados de forma semi-naturalista en color blanco, orientados al noreste. La hilera de la parte superior consta de cinco motivos zoomorfos y un antropomorfo; este último también semi-naturalista de color blanco. La segunda hilera consta de 10 motivos. En la parte superior del panel se encuentran dos círculos concéntricos que constan de cinco anillos de color rojo. 
Teniendo en cuenta los datos obtenidos del registro de las imágenes, se esbozó una serie de cuadros, que ayudan a realizar una comparación objetiva entre las imágenes plasmadas del panel № 01 (Tablas 1 y 2).

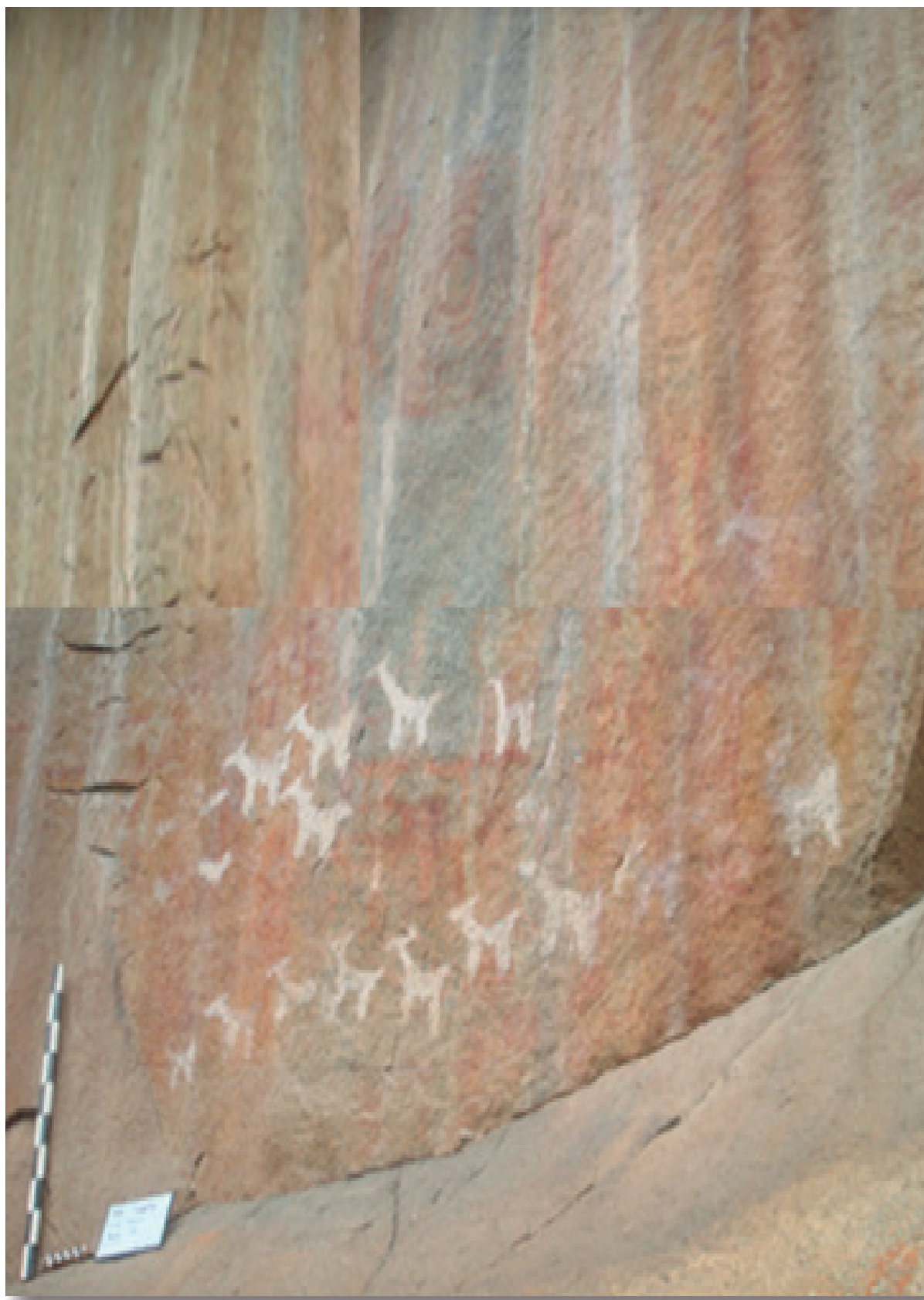

Figura 1. Panel $N^{\circ} 01$, donde se muestra representaciones de probables camélidos y círculos concéntricos. 
Tabla 1.

\begin{tabular}{|c|c|c|c|}
\hline \multicolumn{4}{|c|}{ Tabla Estadística de Panel №1 Mant'o } \\
\hline \multicolumn{2}{|c|}{ Imagen } & \multirow[t]{2}{*}{ Altura } & \multirow[t]{2}{*}{ Ancho } \\
\hline Antropomorfo & $\mathrm{H} 1$ & & \\
\hline \multirow{15}{*}{ Zoomorfo } & LL01 & 0,24 & 0,33 \\
\hline & LL02 & 0,26 & 0,34 \\
\hline & LL03 & 0,24 & 0,34 \\
\hline & LLO4 & 0,29 & 0,34 \\
\hline & LL05 & 0,25 & 0,24 \\
\hline & LL06 & 0,17 & 0,20 \\
\hline & LL07 & 0,20 & 0,25 \\
\hline & LL08 & 0,21 & 0,25 \\
\hline & LL09 & 0,26 & 0,27 \\
\hline & LL10 & 0,30 & 0,32 \\
\hline & LL11 & 0,27 & 0,34 \\
\hline & LL12 & 0,38 & 0,24 \\
\hline & LL13 & 0,31 & 0,34 \\
\hline & LL14 & 0,26 & 0,28 \\
\hline & LL15 & 0,30 & 0,32 \\
\hline \multirow{2}{*}{ Geométrica } & $\mathrm{CC} 1$ & 0,73 & 0,74 \\
\hline & $\mathrm{CC} 2$ & 0,76 & 0,75 \\
\hline
\end{tabular}

Tabla 2.

\begin{tabular}{|c|c|c|c|c|}
\hline \multicolumn{6}{|c|}{ Tabla Estadística de Panel No01 Mant'o } \\
\hline \multirow{4}{*}{ Imagen } & LL01 & Altura & Ancho & Promedio \\
\cline { 2 - 5 } & LL02 & 0,24 & 0,33 & 0,29 \\
\cline { 2 - 5 } & LL03 & 0,24 & 0,34 & 0,30 \\
\cline { 2 - 5 } & LL04 & 0,29 & 0,34 & 0,29 \\
\cline { 2 - 5 } & LL05 & 0,25 & 0,34 & 0,32 \\
\cline { 2 - 5 } & LL06 & 0,17 & 0,24 & 0,25 \\
\cline { 2 - 5 } & LL07 & 0,20 & 0,25 & 0,19 \\
\cline { 2 - 5 } & LL08 & 0,21 & 0,25 & 0,23 \\
\cline { 2 - 5 } & LL09 & 0,26 & 0,27 & 0,23 \\
\cline { 2 - 5 } & LL10 & 0,30 & 0,32 & 0,27 \\
\cline { 2 - 5 } & LL11 & 0,27 & 0,34 & 0,31 \\
\cline { 2 - 5 } & LL12 & 0,38 & 0,24 & 0,31 \\
\cline { 2 - 5 } & LL13 & 0,31 & 0,34 & 0,31 \\
\cline { 2 - 5 } & LL14 & 0,26 & 0,28 & 0,33 \\
\cline { 2 - 5 } & LL15 & 0,30 & 0,32 & 0,27 \\
\hline & & 0,26 & 0,29 & 0,31 \\
\hline
\end{tabular}


Un examen de las magnitudes de los motivos, dimensiones medidas, nos muestra que en general, las imágenes zoomorfas son más anchas que largas; aunque la diferencia entre el ancho y largo son mínimas, de apenas tres centímetros en promedio. El tamaño general de la imágenes varía entre los 0.19 a 0.33 metros, siendo el motivo LL06 el más pequeño, y el motivo LL13 el más grande. A esto podemos agregar que la primera hilada de motivos (LL01-LL05) tiene las dimensiones más regulares, manteniendo un tamaño casi uniforme. La segunda hilada por el contrario (LL06-LL15), tienen las dimensiones más irregulares.

\section{Panel № 02 Mant'o}

Las imágenes del panel № 02 se encuentran en tres grupos, dos hacia la parte superior y uno hacia la parte inferior izquierda del panel (Figs. 2 y 3). En el grupo superior izquierdo se observa dos probables representaciones antropomorfas, con dos imágenes zoomorfas y una imagen amorfa. En el segundo grupo superior se puede ver un ser antropomorfo con cuatro imágenes zoomorfas y una geométrica. Por último en la parte inferior se observa una imagen zoomorfa con siete imágenes geométricas, entre las que se tienen imágenes lineales.

Teniendo en cuenta la descripción realizada y un examen de cada uno de los motivos, se tabularon los datos obtenidos, que ayudan a realizar una comparación objetiva entre las quilcas del panel №02 (Tablas 3, 4, 5 y 6).

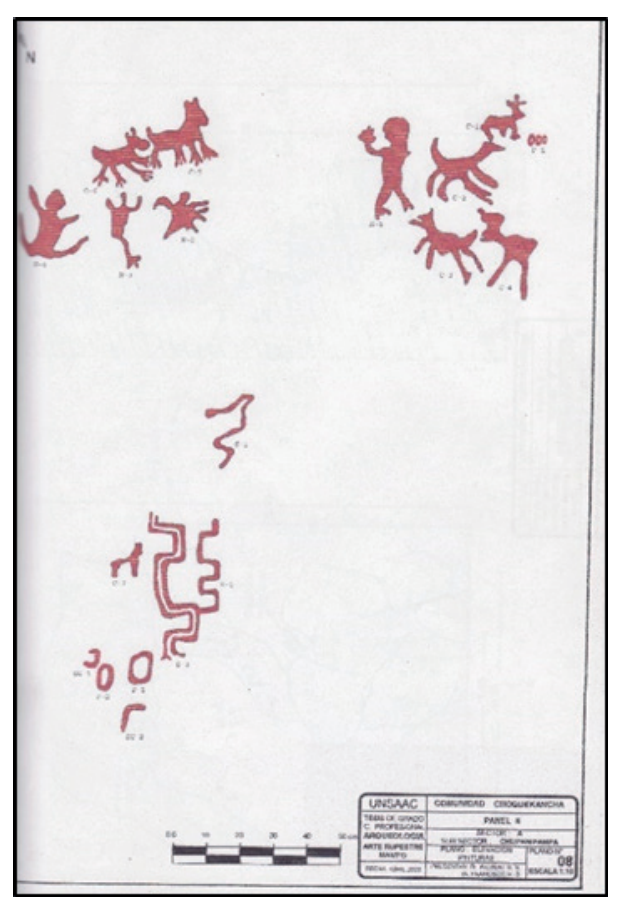

Figura 2. Plano de elevación del paner $N^{\circ} 2$. Tomado de Rodrigo y Huarcaya, 2003.

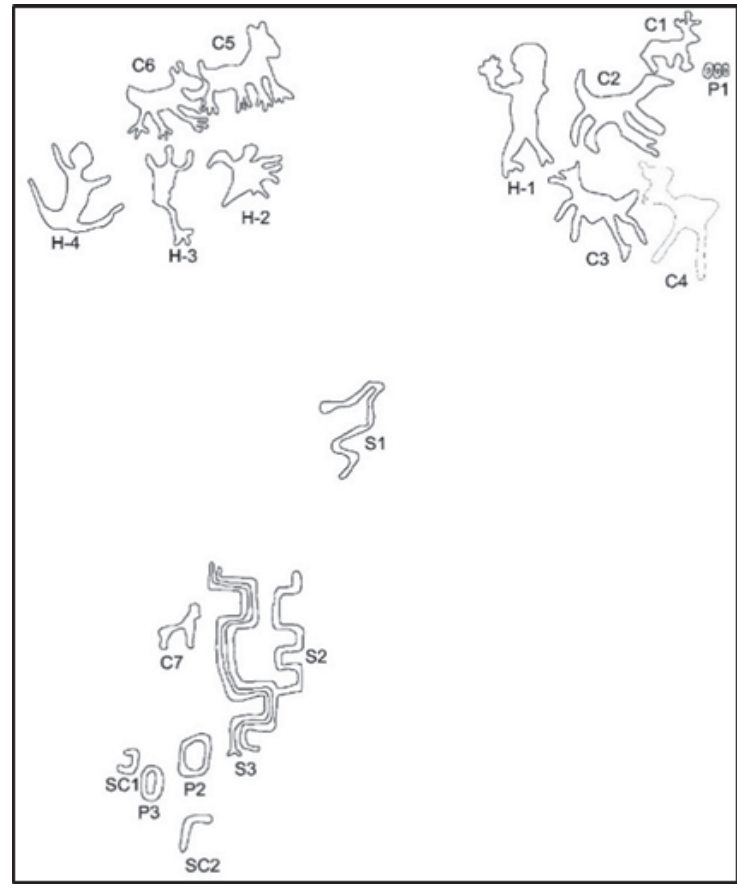

Figura 3. Imagen digitalizada del panel $N^{\circ} 02$, basada en Rodrigo y Huarcaya, 2003. Dibujo por Carlos Rodríguez Béjar. 
Tabla 3.

\begin{tabular}{|c|c|c|c|}
\hline \multicolumn{4}{|c|}{ Tabla Estadística de Panel №02 Mant’o } \\
\hline \multicolumn{2}{|c|}{ Imagen } & \multirow{2}{*}{$\begin{array}{c}\text { Altura } \\
0,31\end{array}$} & \multirow{2}{*}{$\begin{array}{c}\text { Ancho } \\
0,15\end{array}$} \\
\hline \multirow{3}{*}{ Antropomorfo } & $\mathrm{H} 1$ & & \\
\hline & $\mathrm{H} 2$ & 0,23 & 0,11 \\
\hline & $\mathrm{H} 3$ & 0,20 & 0,21 \\
\hline \multirow{7}{*}{ Zoomorfo } & $\mathrm{C} 1$ & 0,14 & 0,13 \\
\hline & $\mathrm{C} 2$ & 0,20 & 0,23 \\
\hline & $\mathrm{C} 3$ & 0,23 & 0,22 \\
\hline & $\mathrm{C} 4$ & 0,27 & 0,18 \\
\hline & C5 & 0,21 & 0,21 \\
\hline & $\mathrm{C} 6$ & 0,18 & 0,17 \\
\hline & $\mathrm{C} 7$ & 0,11 & 0,09 \\
\hline \multirow{8}{*}{ Geométrica } & P1 & 0,04 & 0,06 \\
\hline & P2 & 0,10 & 0,07 \\
\hline & P3 & 0,08 & 0,05 \\
\hline & $\mathrm{SC} 1$ & 0,06 & 0,05 \\
\hline & SC2 & 0,09 & 0,07 \\
\hline & S1 & 0,22 & 0,14 \\
\hline & S2 & 0,44 & 0,16 \\
\hline & S3 & 0,29 & 0,07 \\
\hline Amorfa & $\mathrm{H} 2$ & 0,14 & 0,17 \\
\hline
\end{tabular}

Tabla 4.

\begin{tabular}{|c|c|c|c|c|}
\hline \multicolumn{6}{|c|}{ Tabla Estadística de Panel No22 Mant'o (Promedios) } \\
\hline Imagen & & Altura & Ancho & Promedio \\
\hline \multirow{3}{*}{ Antropomorfo } & $\mathrm{H} 1$ & 0,31 & 0,15 & 0,23 \\
\cline { 2 - 5 } & $\mathrm{H} 2$ & 0,23 & 0,11 & 0,17 \\
\cline { 2 - 5 } & $\mathrm{H} 3$ & 0,20 & 0,21 & 0,21 \\
\hline Promedio & 0,25 & 0,16 & 0,20 \\
\hline
\end{tabular}

Tabla 5.

\begin{tabular}{|c|c|c|c|c|}
\hline \multicolumn{5}{|c|}{ Tabla Estadística de Panel N02 Mant'o (Promedios) } \\
\hline \multicolumn{2}{|c|}{ Imagen } & Altura & Ancho & Promedio \\
\hline \multirow{7}{*}{ Zoomorfo } & $\mathrm{C} 1$ & 0,14 & 0,13 & 0,14 \\
\hline & $\mathrm{C} 2$ & 0,20 & 0,23 & 0,22 \\
\hline & C3 & 0,23 & 0,22 & 0,23 \\
\hline & $\mathrm{C} 4$ & 0,27 & 0,18 & 0,23 \\
\hline & $\mathrm{C5}$ & 0,21 & 0,21 & 0,21 \\
\hline & C6 & 0,18 & 0,17 & 0,18 \\
\hline & $\mathrm{C} 7$ & 0,11 & 0,09 & 0,10 \\
\hline \multicolumn{2}{|c|}{ Promedio } & 0,19 & 0,18 & 0,18 \\
\hline
\end{tabular}


Tabla 6.

\begin{tabular}{|c|c|c|c|c|}
\hline \multicolumn{5}{|c|}{ Tabla Estadística de Panel No02 Mant'o (Promedios) } \\
\hline Imagen & & Altura & Ancho & Promedio \\
\hline \multirow{4}{*}{ Geométrica } & P1 & 0,04 & 0,06 & 0,05 \\
\cline { 2 - 5 } & P2 & 0,10 & 0,07 & 0,09 \\
\cline { 2 - 5 } & P3 & 0,08 & 0,05 & 0,07 \\
\cline { 2 - 5 } & SC1 & 0,06 & 0,05 & 0,06 \\
\cline { 2 - 5 } & SC2 & 0,09 & 0,07 & 0,08 \\
\cline { 2 - 5 } & S1 & 0,22 & 0,14 & 0,18 \\
\cline { 2 - 5 } & S2 & 0,44 & 0,16 & 0,30 \\
\cline { 2 - 5 } & S3 & 0,29 & 0,07 & 0,18 \\
\hline Promedio & & 0,19 & 0,09 & 0,14 \\
\hline
\end{tabular}

Como se puede ver en la tabulación, las imágenes antropomorfas son las más regulares en dimensiones y forma, aunque cabe señalar que no presentan un mismo patrón gráfico. En la imagen H1, al motivo le falta la extremidad superior izquierda y su cabeza es más ancha que los otros motivos antropomorfos del mismo panel. Al motivo antropomorfo H3 lo graficaron sin la extremidad inferior derecha. Sólo la imagen antropomorfa $\mathrm{H} 4$ posee las cuatro extremidades superiores e inferiores características de una imagen antropomorfa común.

Las imágenes zoomorfas tienen dimensiones regulares, es decir que tiene casi el mismo tamaño, pero al igual que las imágenes antropomorfas, no tienen el mismo patrón gráfico; incluso parecen no representar a un mismo motivo zoomorfo. A diferencia del panel № 01, donde todas las imágenes zoomorfas parecen ser representaciones de camélidos, es probable que en el panel № 02 tengamos representaciones de Sérvidos, camélidos y otros animales no identificados.

Las imágenes geométricas son las más irregulares en tanto forma y dimensiones, el patrón grafico nos muestra figuras ovoides, líneas zigzagueantes, y figuras de difícil interpretación. En este sentido la figura amorfa H2 es sin duda la más abstracta, tratándose probablemente de una manifestación netamente cognitiva.

Las imágenes del Panel № 02 muestran manifestaciones planas, con características irregulares. Como mencionamos, aparentemente se orienta a representar principalmente un mundo cognitivo abstracto y particular, que una representación figurativa más realista.

\section{Panel № 03 A Mant’o}

En este panel podemos observar imágenes antropomorfas, de cuerpos rectangulares y extremidades superiores levantadas (Fig. 4). En algunas de estas imágenes se encuentran graficados accesorios en la parte correspondiente a la cabeza. Los motivos zoomorfos por su parte, tienen un patrón gráfico irregular, no poseen características similares entre sí y en algunos casos se encuentran graficadas con extremidades exageradamente largas. Se tiene también imágenes geométricas e imágenes amorfas.

Todos los motivos mencionados se encuentran asociados a una figura principal ubicada en el medio del panel, que presenta elementos decorativos geométricos (Fig. 5). El cuerpo de este motivo es rectangular y sus extremidades superiores, al igual del resto de las imágenes antropomorfas, se hallan levantados. Las características principales han sido tabuladas para una mejor comparación (Tablas 7 , $8,9$ y 10$)$. 


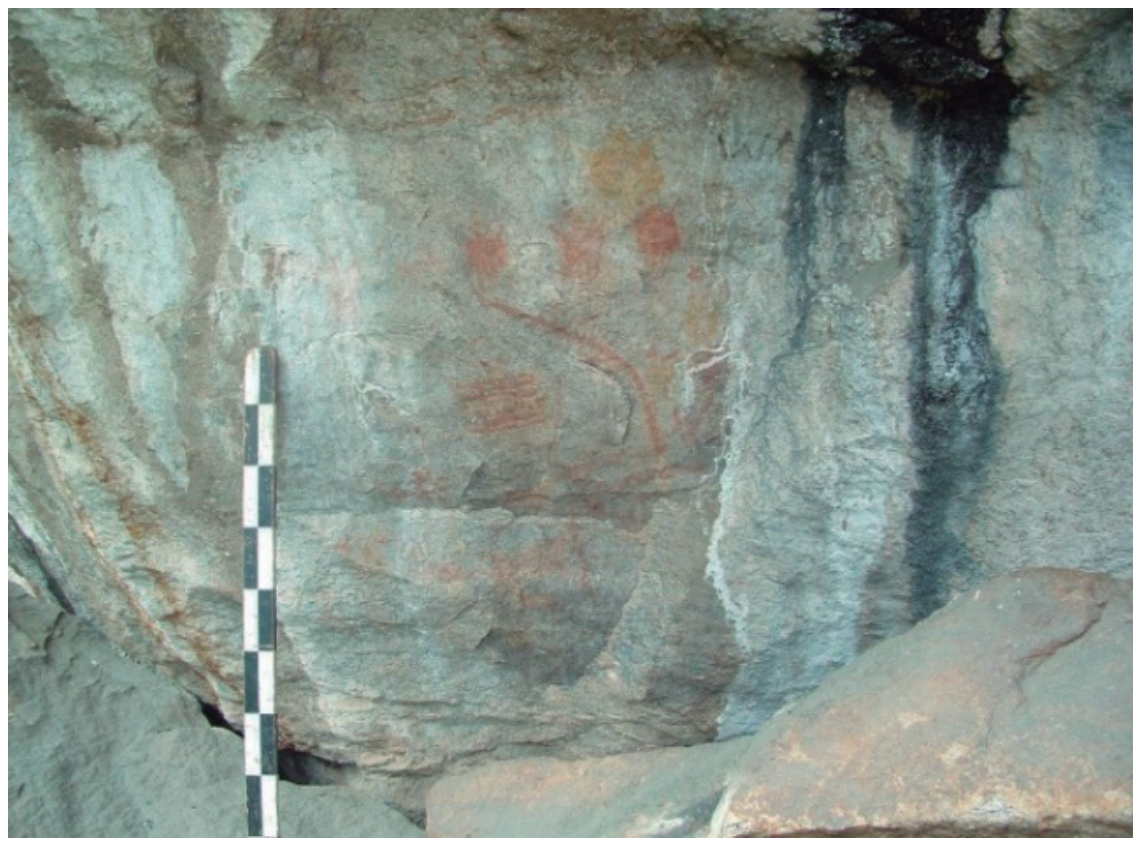

Figura 4. Vista del panel $N^{\circ} 3 A$, donde se muestran imágenes antropomorfas, zoomorfas, entre otras (Imagen Carlos Rodríguez Béjar).

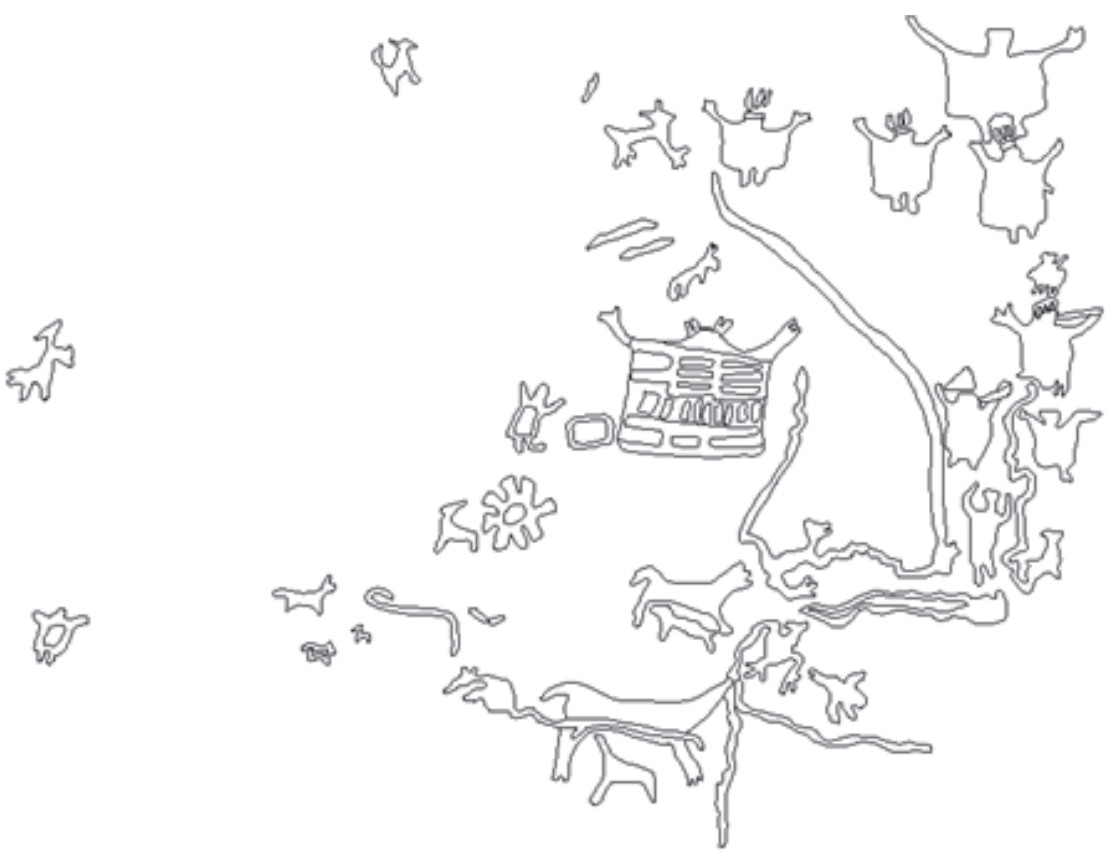

Figura 5. Vista de imágenes digitalizadas y codificadas del panel $N^{\circ} 3^{\underline{a}}$. 
Tabla 7.

\begin{tabular}{|c|c|c|c|}
\hline \multicolumn{4}{|c|}{ Tabla Estadística de Panel N03A Mant'o } \\
\hline \multicolumn{2}{|c|}{ Imagen } & Altura & Ancho \\
\hline \multirow{11}{*}{ Antropomorfo } & $\mathrm{H} 1$ & 0,13 & 0,17 \\
\hline & $\mathrm{H} 2$ & 0,10 & 0,11 \\
\hline & H3 & 0,10 & 0,10 \\
\hline & $\mathrm{H} 4$ & 0,12 & 0,09 \\
\hline & $\mathrm{H} 6$ & 0,10 & 0,11 \\
\hline & $\mathrm{H} 7$ & 0,10 & 0,08 \\
\hline & $\mathrm{H} 8$ & 0,07 & 0,08 \\
\hline & $\mathrm{H} 9$ & 0,10 & 0,05 \\
\hline & $\mathrm{H} 10$ & 0,14 & 0,20 \\
\hline & $\mathrm{H} 11$ & 0,07 & 0,06 \\
\hline & $\mathrm{H} 12$ & 0,06 & 0,05 \\
\hline \multirow{12}{*}{ Zoomorfo } & C1 & 0,06 & 0,05 \\
\hline & $\mathrm{C} 2$ & 0,07 & 0,08 \\
\hline & C3 & 0,02 & 0,02 \\
\hline & C4 & 0,08 & 0,06 \\
\hline & C2-2 & 0,05 & 0,04 \\
\hline & Z1 & 0,02 & 0,03 \\
\hline & PU3 & 0,06 & 0,05 \\
\hline & LL2 & 0,07 & 0,12 \\
\hline & LL3 & 0,05 & 0,07 \\
\hline & LL4 & 0,11 & 0,19 \\
\hline & LL5 & 0,07 & 0,06 \\
\hline & LL6 & 0,04 & 0,06 \\
\hline \multirow{2}{*}{ Geométrica } & SL1 & 0,07 & 0,07 \\
\hline & K1 & 0,03 & 0,05 \\
\hline
\end{tabular}

Tabla 8.

\begin{tabular}{|c|c|c|c|c|}
\hline \multicolumn{5}{|c|}{ Tabla Estadística de Panel Nº3A Mant'o (Promedio) } \\
\hline \multirow{12}{*}{ Antropomorfo } & & Altura & Ancho & Promedio \\
\hline & $\mathrm{H} 1$ & 0,13 & 0,17 & 0,15 \\
\hline & $\mathrm{H} 2$ & 0,10 & 0,11 & 0,11 \\
\hline & $\mathrm{H} 3$ & 0,10 & 0,10 & 0,10 \\
\hline & $\mathrm{H} 4$ & 0,12 & 0,09 & 0,11 \\
\hline & $\mathrm{H} 6$ & 0,10 & 0,11 & 0,11 \\
\hline & $\mathrm{H} 7$ & 0,10 & 0,08 & 0,09 \\
\hline & $\mathrm{H} 8$ & 0,07 & 0,08 & 0,08 \\
\hline & $\mathrm{H} 9$ & 0,10 & 0,05 & 0,08 \\
\hline & $\mathrm{H} 10$ & 0,14 & 0,20 & 0,17 \\
\hline & $\mathrm{H} 11$ & 0,07 & 0,06 & 0,07 \\
\hline & $\mathrm{H} 12$ & 0,06 & 0,05 & 0,06 \\
\hline \multicolumn{2}{|l|}{ Promedio } & 0,10 & 0,10 & 0,10 \\
\hline
\end{tabular}


Tabla 9.

\begin{tabular}{|c|c|c|c|c|}
\hline \multicolumn{5}{|c|}{ Tabla Estadística de Panel No3A Mant'o (Promedio) } \\
\hline \multirow{3}{*}{ Imagen } & & Altura & Ancho & Promedio \\
\hline \multirow{4}{*}{ Zoomorfo } & C1 & 0,06 & 0,05 & 0,06 \\
\cline { 2 - 5 } & C2 & 0,07 & 0,08 & 0,08 \\
\cline { 2 - 5 } & C3 & 0,02 & 0,02 & 0,02 \\
\cline { 2 - 5 } & C4 & 0,08 & 0,06 & 0,07 \\
\cline { 2 - 5 } & C2-2 & 0,05 & 0,04 & 0,05 \\
\cline { 2 - 5 } & Z1 & 0,02 & 0,03 & 0,03 \\
\cline { 2 - 5 } & PU3 & 0,06 & 0,05 & 0,06 \\
\cline { 2 - 5 } & LL2 & 0,07 & 0,12 & 0,10 \\
\cline { 2 - 5 } & LL3 & 0,05 & 0,07 & 0,06 \\
\cline { 2 - 5 } & LL4 & 0,11 & 0,19 & 0,15 \\
\cline { 2 - 5 } & LL5 & 0,07 & 0,06 & 0,07 \\
\cline { 2 - 5 } & LL6 & 0,04 & 0,06 & 0,05 \\
\hline
\end{tabular}

Tabla 10.

\begin{tabular}{|c|c|c|c|c|}
\hline \multicolumn{5}{|c|}{ Tabla Estadística de Panel No3A Mant'o (Promedio) } \\
\hline \multirow{2}{*}{ Imagen } & Altura & Ancho & Promedio \\
\hline \multirow{2}{*}{ Geométrica } & SL1 & 0,07 & 0,07 & 0,07 \\
\cline { 2 - 5 } & K1 & 0,03 & 0,05 & 0,04 \\
\hline \multicolumn{2}{|c|}{ Promedio } & 0,05 & 0,06 & 0,06 \\
\hline
\end{tabular}

Las imágenes antropomorfas son en promedio las de mayor dimensión, teniendo un patrón grafico similar entre ellas, exceptuando la imagen antropomorfa H10, que tiene detalles geométricos en el interior de su cuerpo; esto estiliza la imagen en comparación de las demás que presentan una descripción más naturalista. Por su parte, las imágenes zoomorfas presentan grandes diferencias en forma y dimensión, y no se puede encontrar un patrón gráfico estándar en su diseño. Las imágenes geométricas son las de menor dimensión y son formalmente similares entre ellas.

Aunque la mayor parte de los motivos antropomorfos son similares, no todos tienen los mismos elementos característicos. La imagen antropomorfa H8 solo tiene su extremidad inferior izquierda; de igual forma la imagen central del panel (H10) no fue graficada con sus extremidades inferiores, además, como ya se mencionó reiteradamente tiene figuras geométricas el interior de su cuerpo; y las imágenes H11 y H12 tienen figuras ovaladas en su interior.

Las imágenes zoomorfas son las de mayor diversidad en forma y dimensión. Al igual que las imágenes antropomorfas, se graficaron imágenes mutiladas o con falta de elementos característicos. Las imágenes LL2, LL4 y LL5 no presentan cabezas solo cuellos alargados. 


\section{Panel N $^{\circ} 03$ B Manto}

En este panel, tenemos un patrón grafico donde las imágenes antropomorfas son plasmadas con cuerpos rectangulares y las extremidades superiores levantadas por encima de sus cuerpos. Las imágenes zoomorfas son pocas y con diferentes características. Por su parte, solo se tiene una imagen geométrica la cual tiene una forma rectangular (Figs. 6 y 7)

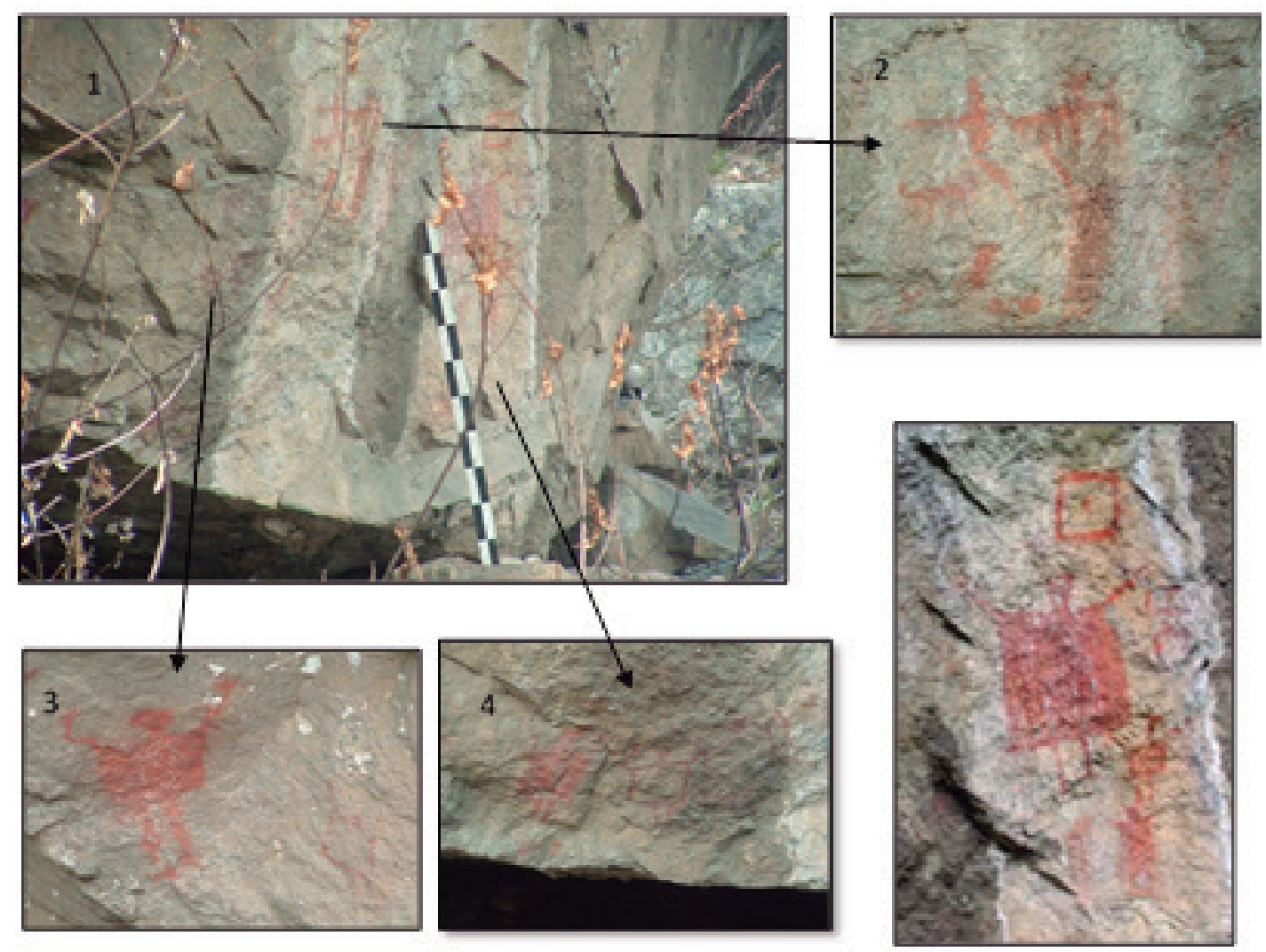

Figura 6. Vista por secciones del panel 3B. 1) vista general del panel de forma diagonal; 2) vista de imágenes amorfas; 3) Vista de imagen antropomorfas $\mathrm{H} 6$ y H7; 3) vista de imágenes antropomorfas $\mathrm{H} 10$ - H15. 5) vista de la parte media y principal del panel (Fotos Carlos Rodriguez Bejar).

A pesar que la mayoría de las imágenes antropomorfas tienen cuerpos rectangulares, tienen formas diversas; incluso las imágenes $\mathrm{H} 4$ y H5, que tienen formas y dimensiones similares, son distintas, ya que la imagen H5 se encuentra unido en forma de protuberancia a la imagen amorfa H3-LL1. Los motivos zoomorfos son apenas tres, y de los geométricos solo tenemos uno, lo que puede indicar que en este panel se dio preferencia a las imágenes antropomorfas. Las características principales de estos motivos han sido tabuladas para una comparación más definida (Tablas 11, 12 y 13). 


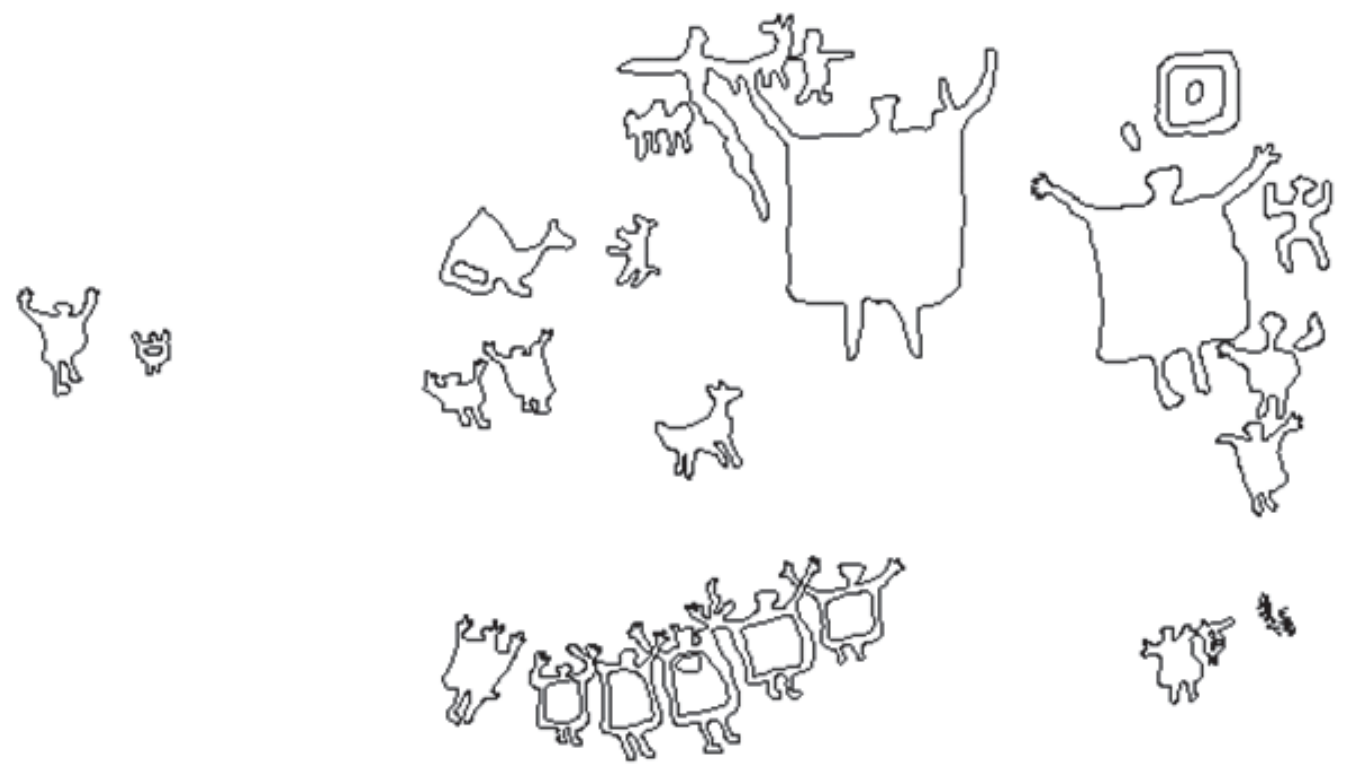

Figura 7. Imagen general digitalizada del panel 3B, se aprecia en forma plana y la dispersión de cada uno de las imágenes, (Dibujo Carlos Rodríguez Béjar).

Tabla 11.

\begin{tabular}{|c|c|c|c|}
\hline \multicolumn{4}{|c|}{ Tabla Estadística de Panel N03B Mant'o } \\
\hline Imagen & & Altura & Ancho \\
\hline \multirow{13}{*}{ Antropomorfo } & $\mathrm{H} 1$ & 0,07 & 0,05 \\
\hline & $\mathrm{H} 2$ & 0,05 & 0,05 \\
\hline & $\mathrm{H} 4$ & 0,17 & 0,18 \\
\hline & H5 & 0,22 & 0,18 \\
\hline & $\mathrm{H} 6$ & 0,08 & 0,06 \\
\hline & $\mathrm{H} 7$ & 0,03 & 0,03 \\
\hline & $\mathrm{H} 8$ & 0,05 & 0,05 \\
\hline & $\mathrm{H} 9$ & 0,06 & 0,05 \\
\hline & $\mathrm{H} 10$ & 0,08 & 0,06 \\
\hline & $\mathrm{H} 16$ & 0,06 & 0,04 \\
\hline & H17 & 0,03 & 0,03 \\
\hline & $\mathrm{H} 18$ & 0,07 & 0,06 \\
\hline & $\mathrm{H} 19$ & 0,08 & 0,08 \\
\hline \multirow{3}{*}{ Zoomorfo } & LL2 & 0,06 & 0,10 \\
\hline & LL3 & 0,07 & 0,06 \\
\hline & PE3 & 0,05 & 0,04 \\
\hline Geométrica & P1 & 0,06 & 0,06 \\
\hline
\end{tabular}


Tabla 12.

\begin{tabular}{|c|c|c|c|c|}
\hline \multicolumn{5}{|c|}{ Tabla Estadística de Panel Nº3B Mant’o (Promedio) } \\
\hline \multirow[t]{7}{*}{ Imagen } & & Altura & Ancho & Promedio \\
\hline & $\mathrm{H} 1$ & 0,07 & 0,05 & 0,06 \\
\hline & $\mathrm{H} 2$ & 0,05 & 0,05 & 0,05 \\
\hline & $\mathrm{H} 4$ & 0,17 & 0,18 & 0,18 \\
\hline & H5 & 0,22 & 0,18 & 0,20 \\
\hline & H6 & 0,08 & 0,06 & 0,07 \\
\hline & $\mathrm{H} 7$ & 0,03 & 0,03 & 0,03 \\
\hline \multirow[t]{7}{*}{ Antropomorfo } & H8 & 0,05 & 0,05 & 0,05 \\
\hline & H9 & 0,06 & 0,05 & 0,06 \\
\hline & $\mathrm{H} 10$ & 0,08 & 0,06 & 0,07 \\
\hline & H16 & 0,06 & 0,04 & 0,05 \\
\hline & $\mathrm{H} 17$ & 0,03 & 0,03 & 0,03 \\
\hline & H18 & 0,07 & 0,06 & 0,07 \\
\hline & $\mathrm{H} 19$ & 0,08 & 0,08 & 0,08 \\
\hline Promedio & & 0,08 & 0,07 & 0,08 \\
\hline
\end{tabular}

Tabla 13.

\begin{tabular}{|c|c|c|c|c|}
\hline \multicolumn{5}{|c|}{ Tabla Estadística de Panel No3B Mant'o (Promedio) } \\
\hline \multirow{2}{*}{ Imagen } & Altura & Ancho & Promedio \\
& LL2 & 0,06 & 0,10 & 0,08 \\
\cline { 2 - 5 } Zoomorfo & LL3 & 0,07 & 0,06 & 0,07 \\
\cline { 2 - 5 } & PE3 & 0,05 & 0,04 & 0,05 \\
\hline Promedio & 0,06 & 0,07 & 0,06 \\
\hline
\end{tabular}

Estadísticamente encontramos que la imagen antropomorfa H5 es la más grande, en contraparte las imágenes H7 y H17 son las más pequeñas. Y si observamos el cuadro de promedios más detenidamente observaremos, que las dimensiones varían constantemente sin encontrar algún patrón (ver Tabla 12).

Las imágenes zoomorfas son más parecidas en sus dimensiones, variando por uno o dos centímetros de diferencia (Tabla 13). La variación en las magnitudes no es tan abismal como las imágenes antropomorfas, aunque cabe recalcar, que a nivel formal si existe una clara diferencia.

La imagen geométrica descrita presenta una tamaño, que, a pesar estar en el promedio de la mayoría de las imágenes, es pequeño al lado de las imágenes principales H4 y H5.

\section{Panel Nº 04 Mant'o}

Probablemente se trata del panel con la mayor cantidad de motivos (Figs. 8 y 9). Destacan principalmente las imágenes zoomorfas, 99 motivos, encontrándose una gran diversidad de formas gráficas con diferentes escalas; incluso con técnicas de producción diferenciadas.

El mayor número de motivos zoomorfos, 49 , fue producido mediante trazo simple, constituyendo la mitad de imágenes zoomorfas identificadas en el panel hasta ahora. Las formas con doble trazo son 
el segundo grupo con mayor cantidad de imágenes; al que le sigue las imágenes amorfas con ocho motivos; las composiciones geométricas con siete motivos; y las imágenes compuestas con seis motivos; y finalmente cuatro motivos abstractos.

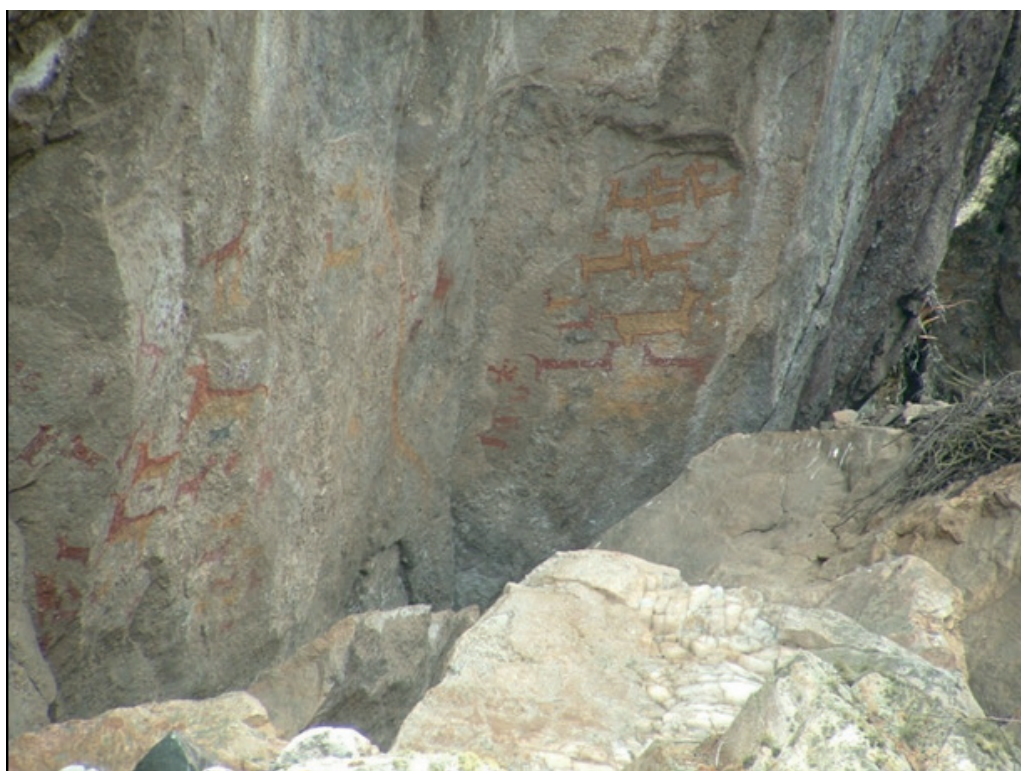

Figura 8. Vista del panel $N^{\circ} 4$, se encuentra conformado por un alto porcentaje de imágenes zoomorfas, solo se visualiza una imagen antropomorfa (Imagen Carlos Rodríguez Béjar).

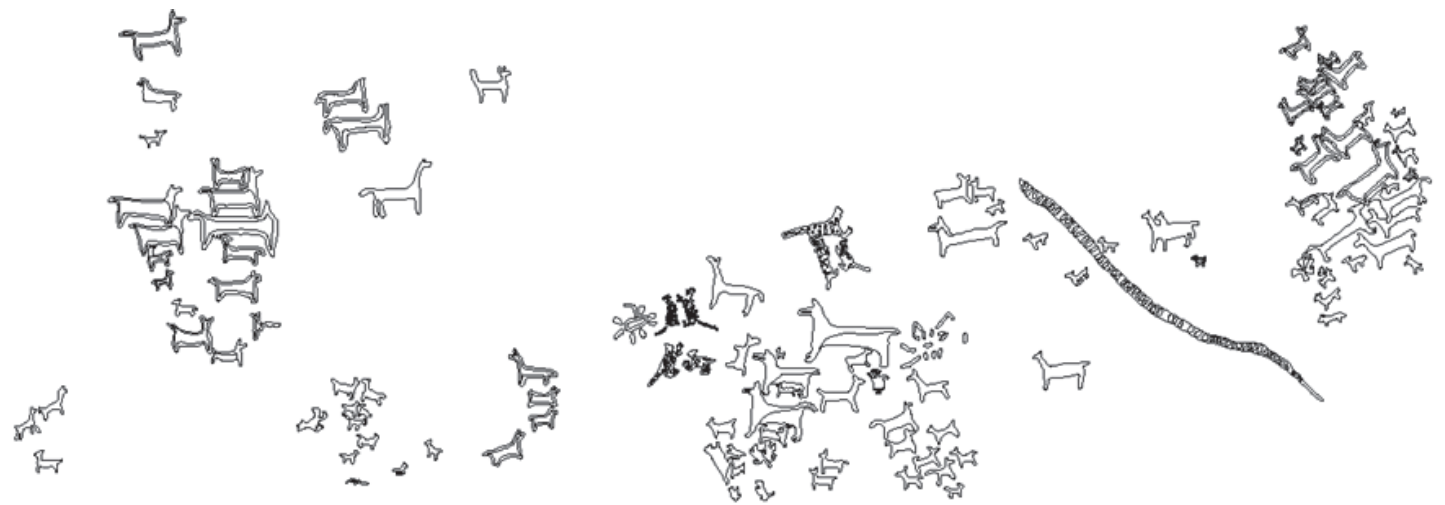

Figura 9. Imagen digitalizada y codificada del panel N4 (Dibujo Carlos Rodriguez Bejar)

Las imágenes zoomorfas de trazo simple, son las únicas imágenes sometidas al análisis de dimensión (Tabla 14), debido a que el objetivo de este análisis es la posterior comparación con las imágenes del panel №01. 
Tabla 14.

\begin{tabular}{|c|c|c|c|c|}
\hline \multicolumn{5}{|c|}{ Tabla Estadística de Panel 4 Mant'o } \\
\hline \multicolumn{2}{|c|}{ Imagen } & Altura & Ancho & Promedio \\
\hline \multirow{49}{*}{ Zoomorfo } & Z1 & 0,08 & 0,12 & 0,10 \\
\hline & Z2 & 0,25 & 0,33 & 0,29 \\
\hline & LL5 & 0,17 & 0,18 & 0,18 \\
\hline & LL14 & 0,08 & 0,11 & 0,10 \\
\hline & LL19 & 0,16 & 0,13 & 0,15 \\
\hline & LL20 & 0,15 & 0,11 & 0,13 \\
\hline & LL21 & 0,10 & 0,13 & 0,12 \\
\hline & LL22 & 0,10 & 0,13 & 0,12 \\
\hline & LL23 & 0,12 & 0,11 & 0,12 \\
\hline & LL24 & 0,07 & 0,06 & 0,07 \\
\hline & LL25 & 0,07 & 0,08 & 0,08 \\
\hline & LL26 & 0,07 & 0,10 & 0,09 \\
\hline & LL27 & 0,09 & 0,08 & 0,09 \\
\hline & PE1 & 0,06 & 0,09 & 0,08 \\
\hline & PE2 & 0,06 & 0,06 & 0,06 \\
\hline & LL32 & 0,28 & 0,26 & 0,27 \\
\hline & AL5 & 0,19 & 0,16 & 0,18 \\
\hline & LL34 & 0,11 & 0,12 & 0,12 \\
\hline & LL35 & 0,15 & 0,19 & 0,17 \\
\hline & LL36 & 0,09 & 0,12 & 0,11 \\
\hline & LL37 & 0,13 & 0,14 & 0,14 \\
\hline & LL38 & 0,12 & 0,12 & 0,12 \\
\hline & LL39 & 0,11 & 0,12 & 0,12 \\
\hline & LL40 & 0,13 & 0,14 & 0,14 \\
\hline & LL41 & 0,17 & 0,22 & 0,20 \\
\hline & LL42 & 0,17 & 0,22 & 0,20 \\
\hline & LL46 & 0,10 & 0,13 & 0,12 \\
\hline & LL47 & 0,06 & 0,11 & 0,09 \\
\hline & LL49 & 0,05 & 0,04 & 0,05 \\
\hline & PE3 & 0,07 & 0,09 & 0,08 \\
\hline & LL51 & 0,16 & 0,17 & 0,17 \\
\hline & LL52 & 0,11 & 0,12 & 0,12 \\
\hline & LL53 & 0,07 & 0,08 & 0,08 \\
\hline & LL55 & 0,08 & 0,10 & 0,09 \\
\hline & LL56 & 0,07 & 0,09 & 0,08 \\
\hline & LL71 & 0,05 & 0,06 & 0,06 \\
\hline & LL72 & 0,11 & 0,14 & 0,13 \\
\hline & LL75 & 0,05 & 0,08 & 0,07 \\
\hline & LL77 & 0,15 & 0,79 & 0,47 \\
\hline & LL79 & 0,27 & 0,32 & 0,30 \\
\hline & LL82 & 0,17 & 0,28 & 0,23 \\
\hline & LL83 & 0,07 & 0,11 & 0,09 \\
\hline & LL84 & 0,08 & 0,11 & 0,10 \\
\hline & LL85 & 0,10 & 0,12 & 0,11 \\
\hline & LL85-5 & 0,17 & 0,26 & 0,22 \\
\hline & LL86 & 0,11 & 0,14 & 0,13 \\
\hline & LL87 & 0,11 & 0,14 & 0,13 \\
\hline & LL88 & 0,10 & 0,13 & 0,12 \\
\hline & $\mathrm{Z5}$ & 0,06 & 0,12 & 0,09 \\
\hline \multicolumn{2}{|c|}{ Promedio } & 0,12 & 0,15 & 0,13 \\
\hline
\end{tabular}


Como se puede advertir en la tabla, el motivo LL77, es la de mayor dimensión, teniendo un promedio de 0.47 metros, mientras que el motivo LL49 es en cambio el de menor dimensión teniendo un promedio de 0.05 metros. Estos datos nos indica una diversidad de tamaños, y no se encuentra un patrón uniforme en las dimensiones obtenidas.

\section{AnÁlisis Comparativo}

Como precisamos en la parte metodológica, para las comparaciones entre los paneles y motivos analizados se utilizará la "perspectiva artefactual", en tres categorías fijas, que son la técnica, la forma y el estilo.

\section{LA TÉCNICA}

La primera categoría comparativa es la técnica. Aquí tomaremos en cuenta los procedimientos utilizados en la elaboración de los motivos, teniendo como premisa que al producirla estos materiales las personas solemos dejar ciertas características de nuestra mano de obra, las que pueden ser medibles e identificables. De acuerdo a esto, cada una de las imágenes fue sujeta a medición para luego ser procesados estadísticamente.

El cuadro estadístico de las imágenes zoomorfas del panel № 01 (Tabla 15) muestran una simetría entre la altura y el ancho teniendo una moda de 0.26 y 0.34 , siendo valores muy parecidos en su media y mediana. Esto permite concluir que las imágenes zoomorfas tienen un tamaño regular, siendo esta parte de la tendencia en la técnica del autor que las produjo.

El cuadro estadístico del Panel N02 de imágenes zoomorfas (Tabla 16) muestra, al igual que el panel $\mathrm{N}^{\circ} 01$, una simetría entre la altura y el ancho; sin embargo, no presenta una moda estadística a pesar de tener un rango y rango intercuartil menor al del anterior panel. Esto permite concluir que las imágenes zoomorfas de este panel tienen una tendencia regular sin caer en coincidencia de tamaño.

El Panel N03 A de imágenes zoomorfas (Tabla 17) presentan un coeficiente de variación muy alto, debido a que los motivos exponen dimensiones heterogéneas. De aquí se puede concluir que hubo una preferencia técnica de producir motivos con diversos tamaños.

De otro lado, la diferencia entre la altura y el ancho es muy grande entre los motivos zoomorfos del Panel N04; siendo en promedio más anchas que altas (Tabla 18). Así mismo, el coeficiente de variación y el rango en el ancho son claramente altos, lo que muestra motivos de dimensiones heterogeneas.

En este análisis comparativo de imágenes zoomorfas se exceptuó al Panel Nº3B por no tener una muestra suficientemente alta. Para seguir con la comparación se elaboró otro cuadro, donde se muestran los promedios entre la altura y el ancho de los paneles analizados (Tabla 19).

Los datos estadísticos muestran una incompatibilidad de técnica entre las imágenes zoomorfas de los paneles analizados, puesto que el panel $\mathrm{N}^{\circ} 01$ expone motivos de un tamaño homogéneo; el panel $\mathrm{N}^{\circ} 02$ no tiene dos o más imágenes con el mismo tamaño a diferencia del resto de paneles; el panel $\mathrm{N}^{\circ}$ 03B no muestra imágenes más pequeñas y un coeficiente de variación alto; mientras que el panel $\mathrm{N}^{\circ}$ 04 que muestra motivos de tamaño heterogéneo. A partir de esto, se puede concluir inicialmente que: Panel $\mathrm{N}^{\circ} 01 \neq$ Panel $\mathrm{N}^{\circ} 02 \neq$ Panel $\mathrm{N}^{\circ} 03 \mathrm{~A} \neq$ Panel $\mathrm{N}^{\circ} 04$

Las imágenes antropomorfas que son susceptibles al análisis comparativo se encuentran el panel $\mathrm{N}^{\circ} 03 \mathrm{~A}$ y $03 \mathrm{~B}$ (Tabla 20). Aquí se tiene en cuenta que el panel $\mathrm{N}^{\circ} 01 \mathrm{y} \mathrm{N}^{\circ} 02$ tienen una muestra relacionada muy baja y el panel $\mathrm{N}^{\circ} 04$ no presentan imágenes antropomorfas. 
Tabla 15.

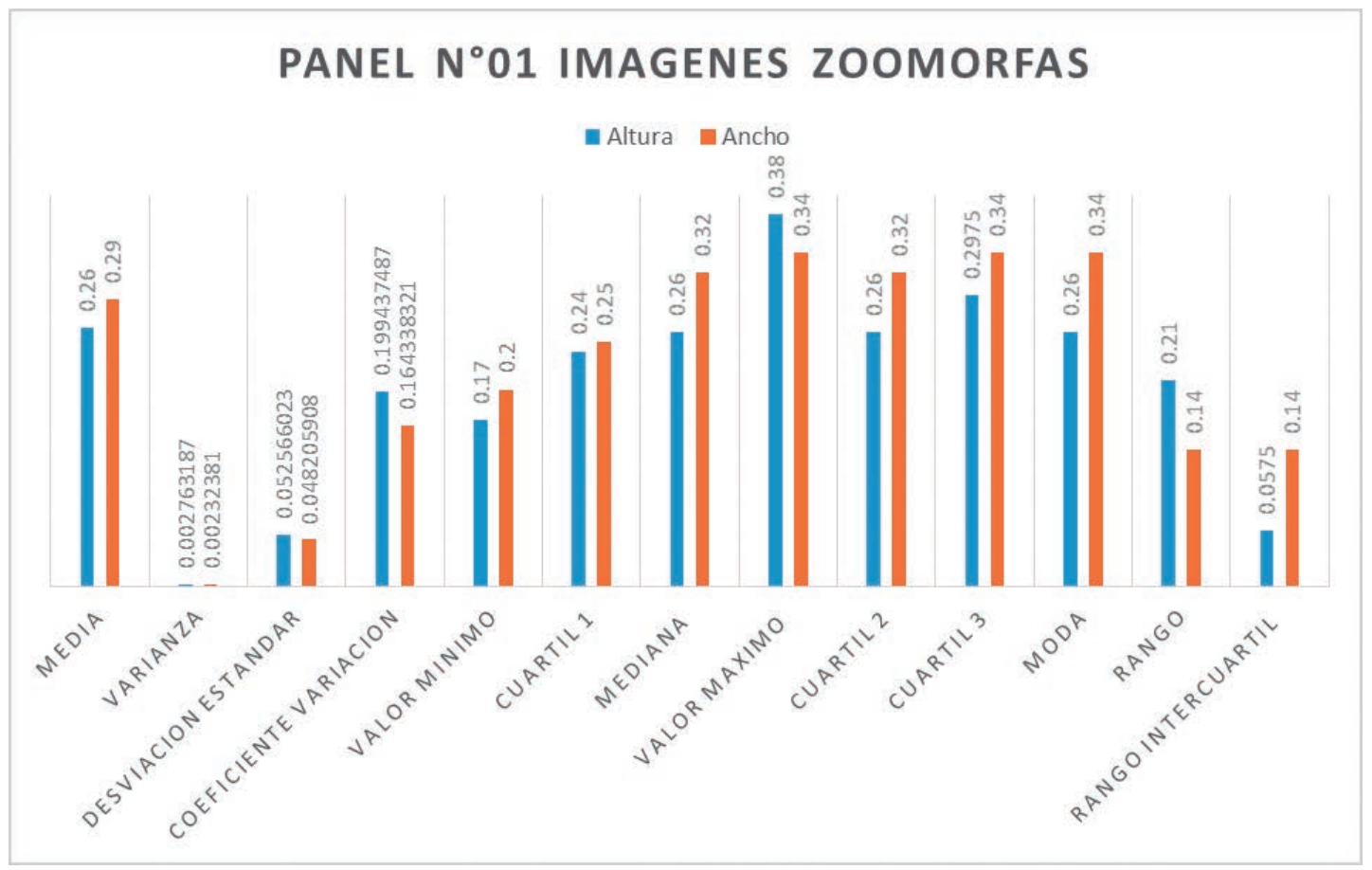

Tabla 16.

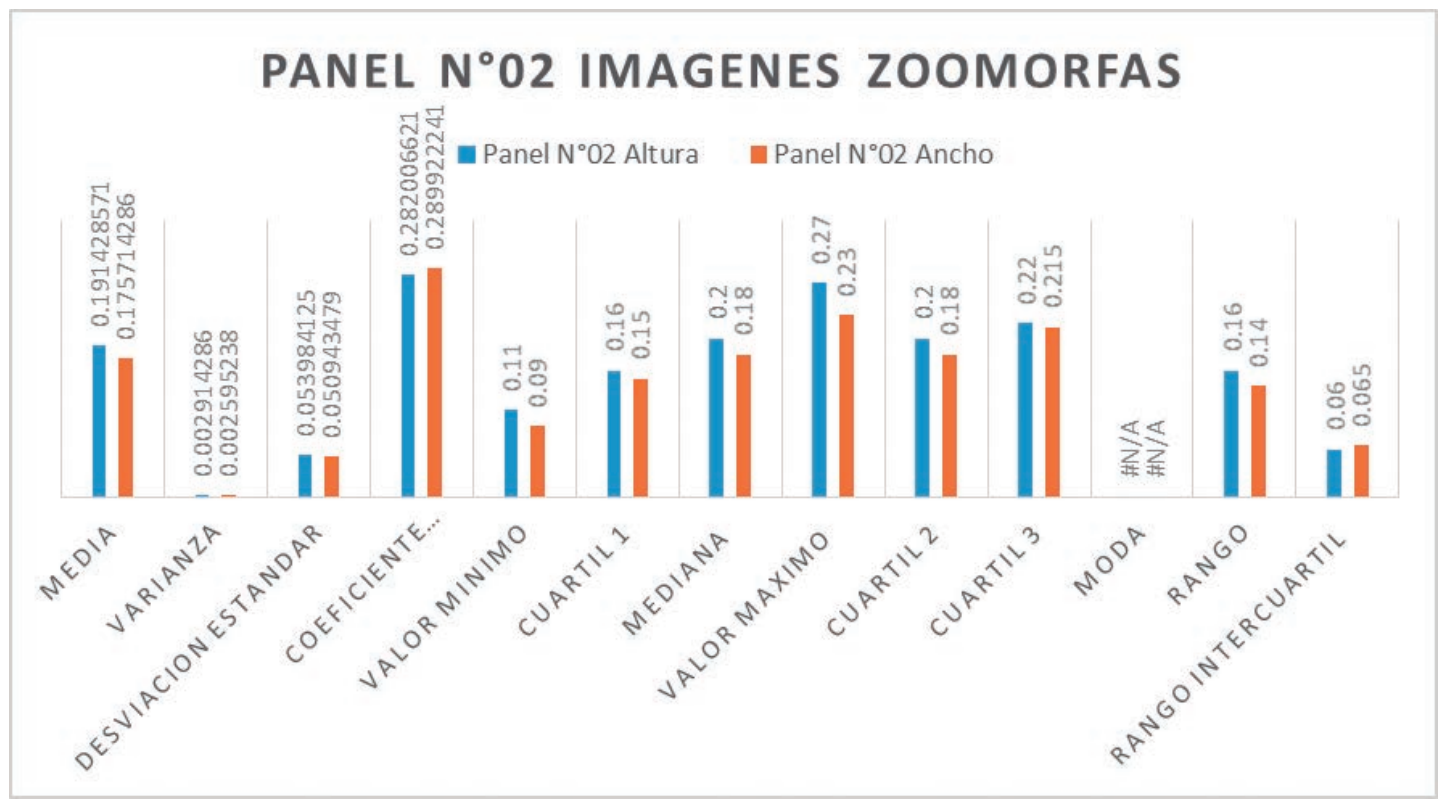


Tabla 17.

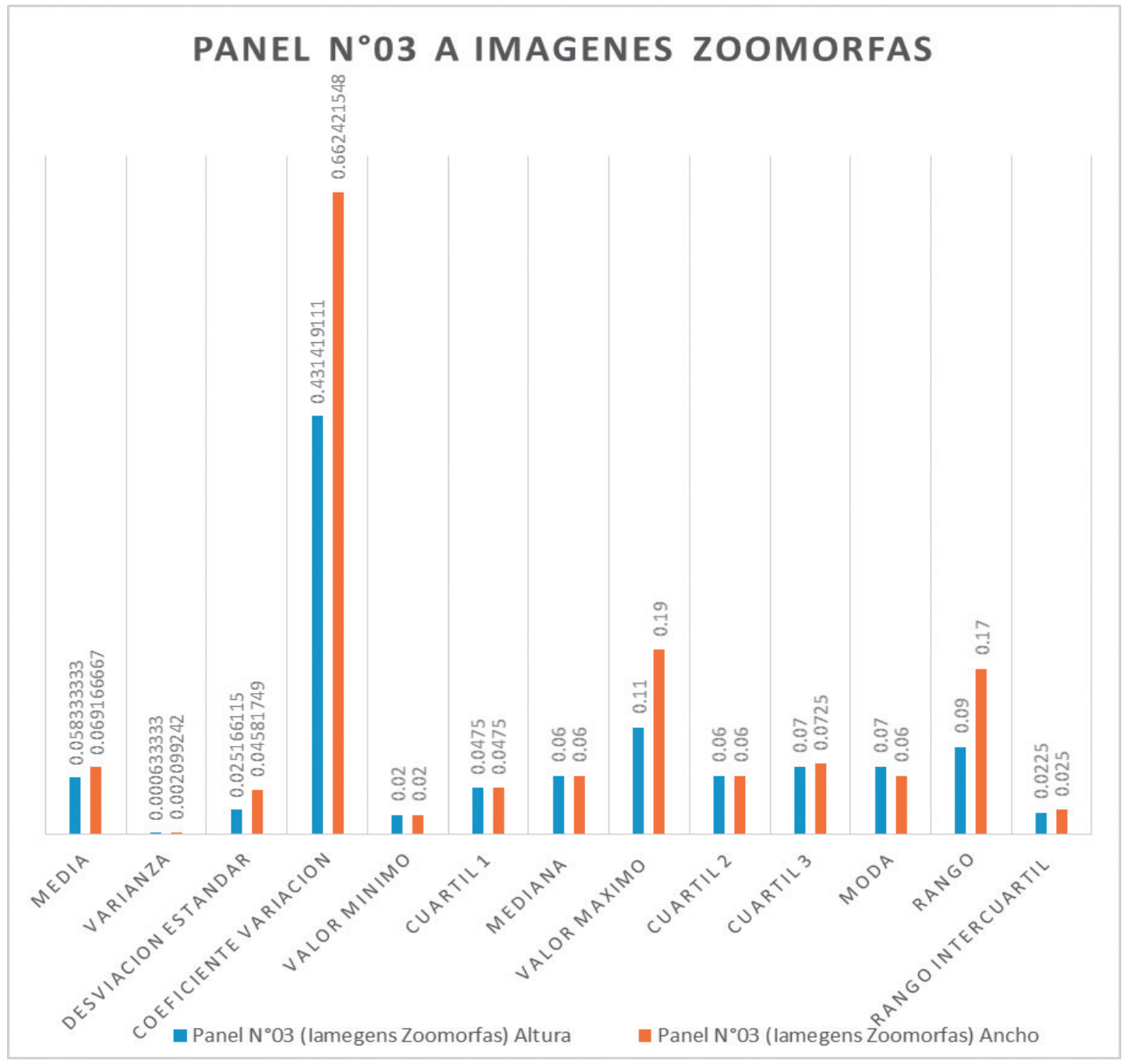

Los datos obtenidos en la tabla 20, nos muestran una regularidad en los valores estadísticos entre ambos paneles teniendo un coeficiente de variación mayor al resto de valores, esto indica que ambos paneles presentan imágenes con dimensiones heterogéneas. Sin embargo el coeficiente de variación del panel $\mathrm{N}^{\circ}$ 03B es mayor al del panel $\mathrm{N}^{\circ}$ 03A. De acuerdo a esto podemos establecer que existe un 92.70\% de probabilidad que ambos paneles presentan la misma técnica en el graficado de imágenes antropomorfas.

\section{La forma}

La segunda categoría comparativa es la forma; donde se buscó patrones y diferencias entre las imágenes de los diferentes paneles analizados. De acuerdo a esto se realizó la descripción individual de cada imagen de forma independiente, teniendo los siguientes resultados comparativos. 
Tabla 18.

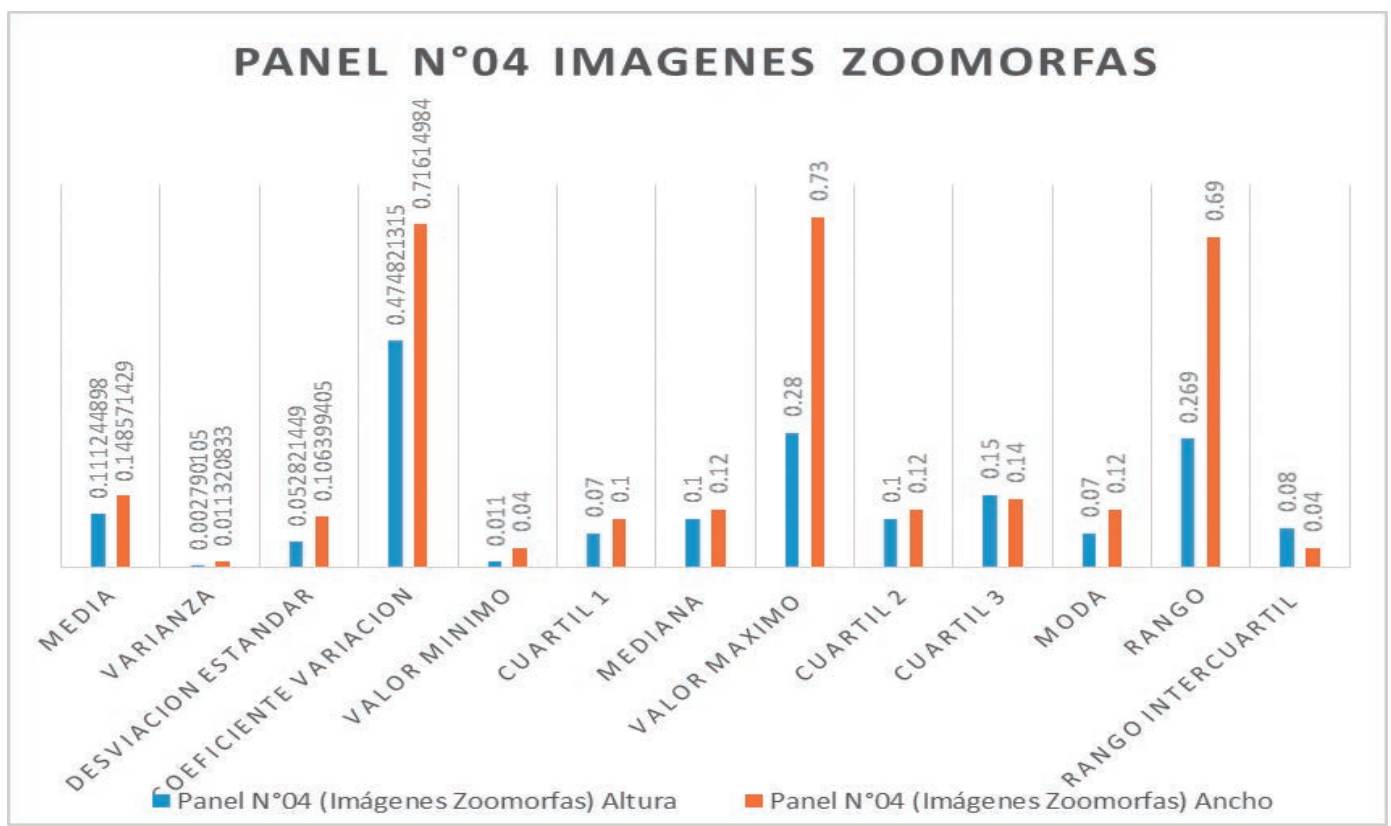

Tabla 19.

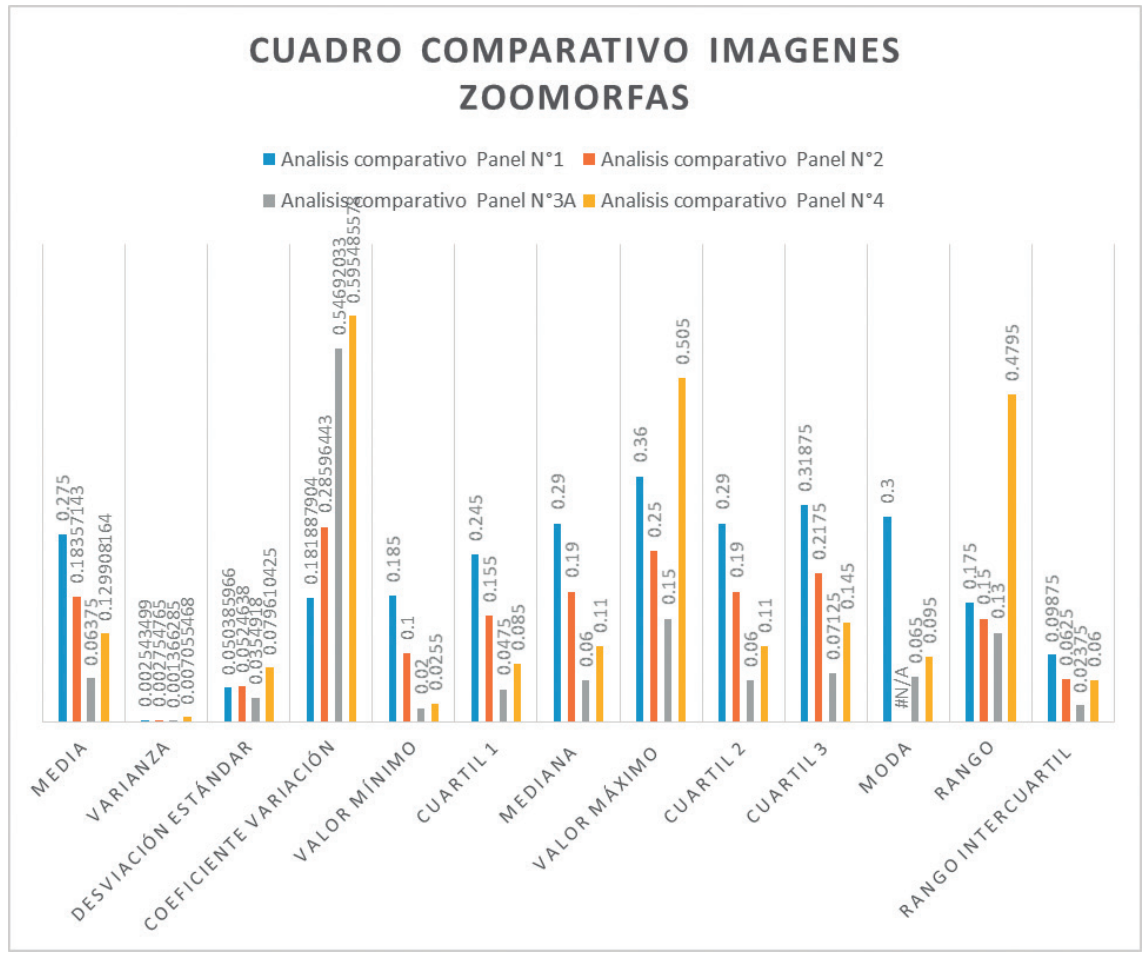


A) Imágenes antropomorfas: La imagen antropomorfa del panel $\mathrm{N}^{\circ} 01$ se encuentra esbozada de frente con una silueta delgada y cuatro extremidades, en cambio en el panel $N^{\circ} 02$ tenemos tres imágenes de silueta delgada, una de ellas tiene 4 extremidades y 2 de ellas tienen solo 3 extremidades. Esta variación demuestra una diferencia formal en la realización de los motivos.

Las imágenes antropomorfas del panel $\mathrm{N}^{\circ}$ 03A y 03B fueron esbozadas con cuerpos rectangulares, lo que implica una similitud formal entre ambos paneles y diferencias marcadas con los paneles $\mathrm{N}^{\circ} 01$ y 02. A partir de esto se puede concluir que: Panel $\mathrm{N}^{\circ} 01 \neq$ Panel $\mathrm{N}^{\circ} 02 \neq$ Panel $\mathrm{N}^{\circ}$ 03A $=$ Panel $\mathrm{N}^{\circ}$ 03B.

B) Las imágenes zoomorfas: Se encuentran claras diferencias entre los paneles analizados, exceptuando los paneles $\mathrm{N}^{\circ}$ 03A y 03B, siendo éstos los únicos que comparten similitudes forma en sus motivos zoomorfos.

Tabla 20.

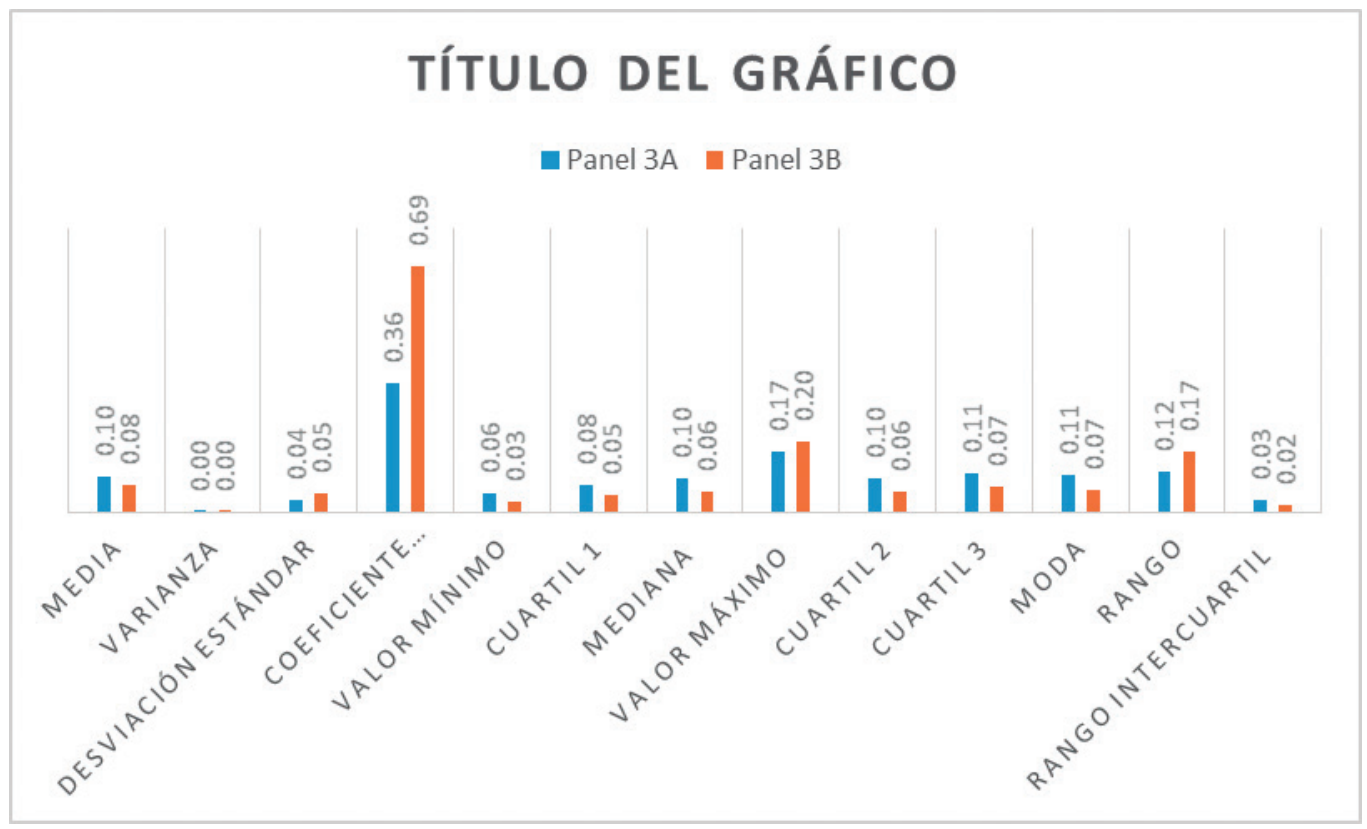

En el panel $\mathrm{N}^{\circ} 01$, el común denominador representativo son camélidos esbozados de perfil con dos extremidades inferiores (patas), extremidad superior y orejas. El panel $\mathrm{N}^{\circ} 02$ muestran imágenes zoomorfas con cuatro extremidades inferiores y cabezas con posibles cornamentas. El panel N 03A, por su parte muestra imágenes zoomorfas con cuatro extremidades inferiores y sin cabezas. El panel $\mathrm{N}^{\circ}$ 03B muestra pocas imágenes zoomorfas por lo que no ha sido considerado en este análisis. Finalmente el panel $\mathrm{N}^{\circ} 04$ muestra una gran variedad de imágenes zoomorfas encontrándose hasta seis variaciones formales, lo que muestra una gran diferencia con el resto de paneles analizados.

De acuerdo a lo anterior se tiene: Panel $\mathrm{N}^{\circ} 01 \neq$ Panel $\mathrm{N}^{\circ} 02 \neq$ Panel $^{\circ} 03 \mathrm{~A} \neq$ Panel $^{\circ} 04$

\section{EL ESTILO}

Entendiendo estilo con la tendencia representativa de los motivos, tenemos el siguiente resultado, que se basa en las descripciones de los motivos anteriormente expuestos: 
1. Panel $N^{\circ}$ 01: Naturalista. Manufactura burda.

2. Panel $\mathrm{N}^{\circ}$ 02: Naturalista-amorfa. Manufactura burda.

3. Panel No 03 A: Estilizada naturalista. Manufactura Burda.

4. Panel No 03 B: Estilizada naturalista. Manufactura Burda.

5. Panel $\mathrm{N}^{\circ}$ 04: Estilizada naturalista.

La variación indica queal la tendencia representativa y de manufactura utilizada en la producción de los paneles es diverso encontrando solo un patrón entre los paneles $\mathrm{N}^{\circ} 03 \mathrm{~A}$ y $03 \mathrm{~B}$. Así tenemos: Panel $\mathrm{N}^{\circ} 01 \neq$ Panel $\mathrm{N}^{\circ} 02 \neq$ Panel $\mathrm{N}^{\circ} 03 \mathrm{~A}=$ Panel $\mathrm{N}^{\circ} 03 \mathrm{~B} \neq$ Panel $\mathrm{N}^{\circ} 04$.

\section{CONCLUSIONES}

En la primera categoría comparativa; la técnica, se determinó que los paneles $\mathrm{N}^{\circ} 01, \mathrm{~N}^{\circ} 02, \mathrm{~N}^{\circ} 03 \mathrm{~A}$ y $\mathrm{N}^{\circ} 04$ son incompatibles. De esta manera: Panel $\mathrm{N}^{\circ} 01 \neq$ Panel $\mathrm{N}^{\circ} 02 \neq$ Panel $\mathrm{N}^{\circ} 03 \mathrm{~A} \neq$ Panel $\mathrm{N}^{\circ} 04$.

La segunda categoría comparativa, la forma, usada para analizar las imágenes antropomorfas y zoomorfas por separado, resultó en una incompatibilidad en los cuatro paneles exceptuando los paneles $\mathrm{N}^{\circ} 03 \mathrm{~A}$ y $\mathrm{N}^{\circ}$ 03B. De esta manera: Panel $\mathrm{N}^{\circ} 01 \neq$ Panel $\mathrm{N}^{\circ} 02 \neq$ Panel $\mathrm{N}^{\circ} 03 \mathrm{~B}=$ Panel $\mathrm{N}^{\circ} 03 \mathrm{~B} \neq$ Panel $\mathrm{N}^{\circ} 04$.

El mismo resultado, donde se tiene una incompatibilidad en los cuatro paneles -exceptuando los paneles $\mathrm{N}^{\circ} 03 \mathrm{~A}$ y $\mathrm{N}^{\circ} 03 \mathrm{~B}-$, se obtuvo en la tercera categoría, el estilo.

Las tres categorías comparativas usadas desde una perspectiva artefactual, permiten proponer que los panales con quilcas $\mathrm{N}^{\circ} 03 \mathrm{~A}$ y $03 \mathrm{~B}$ fueron probablemente producidos en un mismo evento usando la misma técnica de manufactura, los que difieren con los demás paneles que a su vez son incompatibles entre sí.

Así mismo se interpreta que en Mant'o se tuvo cuatro eventos de representación gráfica; la del panel $\mathrm{N}^{\circ} 01$; panel $\mathrm{N}^{\circ} 02$, Los paneles $\mathrm{N}^{\circ} 03$ A y $03 \mathrm{~B}$ y el panel $\mathrm{N}^{\circ} 04$. Esto tiene implicancias a nivel cultural y cronológico, que pueden ser posteriormente abordadas ampliando los estudios.

\section{BibliografíA}

\section{ECHEVARRÍA LÓPEZ ,Gori-Tumi}

2003 "Petroglifos en la cuenca del río Cachiyacu, metodología y registro en contexto de explotación petrolera”. En: Ponencia presentada al VI Simposio Internacional de Arte Rupestre. Jujuy, Argentina.

\section{ECHEVARRÍA LÓPEZ, Gori-Tumi}

2008 Choquequirao: Un Estudio Arqueológico de su arte figurativo. Hipocampo Editores, Lima.

RODRIGO ROJAS, Wilbert y HUARCAYA QUISPE, Francisco

2003 “Investigación Arqueológica en Arte Rupestre de Mant'o, Molino, Chawaytiri y Wayoq’ari, una Introducción a su Estudio”. Tesis para obtener el Título académico Profesional de Arqueología. Universidad San Antonio Abad del Cusco.

RODRÍGUEZ BÉJAR, Carlos

2016 “Medios de Comunicación Pre-Hispánicos: El Caso Paneles de Mant'o - Lares”. Tesis para obtener el Título académico Profesional de Arqueología. Universidad San Antonio Abad del cusco. 
